\title{
Diastereoselective hydrogenation in the preparation of fine chemicals
}

\section{Review Article}

\section{Author(s):}

Kukula, Pavel; Prins, Roel

Publication date:

2003

\section{Permanent link:}

https://doi.org/10.3929/ethz-b-000053147

Rights / license:

In Copyright - Non-Commercial Use Permitted

Originally published in:

Topics in Catalysis 25(1-4), https://doi.org/10.1023/B:TOCA.0000003096.11191.25 


\title{
Diastereoselective hydrogenation in the preparation of fine chemicals
}

\author{
Pavel Kukula $\mathrm{a}^{\mathrm{a}}$ and Roel Prins ${ }^{\mathrm{b}, *}$ \\ ${ }^{a}$ Solvias AG, P.O. Box, CH-4002 Basel, Switzerland \\ ${ }^{\mathrm{b}}$ Institute for Chemical and Bioengineering, Swiss Federal Institute of Technology (ETH), CH-8093 Zurich, Switzerland
}

\begin{abstract}
Heterogeneous catalytic diastereoselective hydrogenation is reviewed with a special emphasis on its application in the preparation of fine chemicals.
\end{abstract}

KEY WORDS: hydrogenation; heterogeneous catalysts; diastereoselectivity; fine chemicals; chiral auxiliary; amino acids.

\section{Introduction}

The production of chiral compounds is a rapidly growing business with sales of chiral drugs representing more than one-third of all drug sales worldwide [1]. This is mainly due to the fact that the biological messenger molecules and the cell surface receptors, which are studied by medicinal chemists, are chiral; thus, the molecules of the drug must match the symmetry of the messenger molecules and surface receptors. The second reason is the more restrictive policy of testing biologically active compounds, which stipulates that a drug cannot be sold in its racemic form until the effects of all the stereoisomers have been determined. The logistics of testing are simpler for a single isomer; therefore, it is advantageous to produce the desired active stereoisomer of the target compound stereoselectively.

Two strategies are applied to produce optically pure chiral substances: classical stereoselective organic synthesis or stereoselective catalysis. From the industrial point of view, the catalytic processes are preferred [2]. Of these processes, catalytic hydrogenation is one of the most important catalytic methods used in the manufacture of fine chemicals. Three types of catalysts can be used to produce optically pure chiral compounds: homogeneous, heterogeneous and biocatalysts. Homogeneous catalysts are better defined on the molecular level, and it is possible to vary and tailor them. Compared to the homogeneous catalysts, heterogeneous catalysts have the advantages of easy separation, possible recovery and recycling, simple handling, good stability, and availability. These advantages are important in industrial production; thus, this review will focus on the applications of heterogeneous catalysts.

Two methods have been applied in asymmetric catalytic hydrogenation with heterogeneous catalysts: (a) enantioselective hydrogenation, in which the chiral element, necessary for a stereoselective reaction, is

\footnotetext{
* To whom correspondence should be addressed.

E-mail: prins@tech.chem.ethz.ch
}

incorporated into the catalyst (a catalytic amount of the chiral molecule is used to modify the surface of the catalyst), and (b) diastereoselective hydrogenation, in which the chiral element is incorporated into the substrate molecule. (This means that a stoichiometric amount of the chiral molecule (auxiliary) must be used.)

Several reviews of enantioselective hydrogenation have been published [3-5], and a number of successful applications have been described [6-10]. However, high enantioselectivity has been obtained only with a limited number of reactions and substrates [11,12]. The best results were obtained in the hydrogenation of $\alpha$ functionalized ketones on cinchona-modified platinum catalysts (ee up to $98 \%$ ), hydrogenation of $\beta$-functionalized ketones on tartaric acid-modified nickel catalysts (ee up to $98 \%$ ) and in the hydrogenation of selected activated $\mathrm{C}=\mathrm{C}$ bonds on cinchona alkaloid modified palladium catalysts (ee up to $85 \%$ ). The interactions among the substrate, modifier and catalyst in these catalytic systems are specific, and although various studies have been published on the mechanism of enantio differentiation [13-16], the mode of action of these catalysts is not yet understood.

On the other hand, the mechanism of diastereoselective hydrogenation and the origin of diastereoselectivity are more transparent. A covalent bond forms between the prochiral substrate and the chiral auxiliary. Thus, the reactant itself is the source of chirality and induces the formation of a new stereogenic center. The resulting diastereoselectivity depends on the conformational properties of the substrate linked to the chiral auxiliary and on the mode of adsorption on the surface of the catalyst. Diastereoselective hydrogenation is the subject of numerous studies, and several reviews have been published [17-20]. Diastereoselective hydrogenation has been applied in the preparation of optically pure amino acids and amines $[18,19]$ as well as in the synthesis of key intermediates of drug molecules [21-24]. This review focuses on diastereoselective hydrogenation and on recent achievements in this area and on diastereoselec- 
tive hydrogenation, as applied in the preparation of fine chemicals and their intermediates.

\section{Concept of diastereoselective hydrogenation}

As mentioned above, the chiral auxiliary, covalently bonded to the substrate molecule, influences the mode of adsorption and thus, the diastereofacial selectivity. There are several criteria, which the chiral auxiliary must meet. The attachment and detachment of the auxiliary to and from the substrate must be a simple one-step procedure. Moreover, the cleavage of the auxiliary must proceed without racemization, and it must be possible to recycle the auxiliary. In some cases discussed below, the auxiliary is a part of a target molecule and recycling is unnecessary. Since a stoichiometric amount of the chiral auxiliary must be used, it should be readily available from a chirality pool or its preparation should be straightforward. Examples of chiral compounds being added directly to the reaction mixture to catalyze stereoselective hydrogenation of prochiral substrates have also been published [25-27]. In that case, it is sometimes difficult to differentiate between an enantioselective and a diastereoselective reaction (i.e., whether or not the chiral additive interacts more strongly with the catalyst or with the substrate, respectively). When a catalytic amount of a chiral compound results in a marked increase in stereoselectivity, this is indicative of a strong interaction with the catalyst and, thus, of an enantioselective reaction. If, on the other hand, a stoichiometric amount of the chiral additive is necessary to enhance selectivity, the additive probably interacts with the substrate, similar to a diastereoselective reaction. Examples of the "in situ applied chiral auxiliary" are the hydrogenation of isophorone and 1-phenylethanol with $(S)$-proline as the chiral auxiliary [25,26] and the hydrogenation of pyruvic acid oxime with a cinchonidine auxiliary [27]. However, we will only discuss systems, in which the chiral auxiliary is covalently bonded to the substrate prior to the reaction.

Diastereoselective hydrogenation can be used for the stereoselective reduction of various functional groups. Thus, $\mathrm{C}=\mathrm{C}, \mathrm{C}=\mathrm{O}$, and $\mathrm{C}=\mathrm{N}$ groups, as well as prochiral aromatics and heteroaromatics, were diastereoselectively hydrogenated. In some cases, the hydrogenation of aromatics and heteroaromatics proceeds via an olefinic intermediate and diastereoselective hydrogenation is then based on the hydrogenation of the $\mathrm{C}=\mathrm{C}$ bond. Nevertheless, these examples will be discussed below in relation to the original substrate. Some examples of the diastereoselective hydrogenation of various $\mathrm{C}=\mathrm{C}, \mathrm{C}=\mathrm{O}$, and $\mathrm{C}=\mathrm{N}$ bonds were described in reviews by Besson [17] and Tungler [18]. Therefore, only a few of the older results will be summarized. We will pay more attention to results that have not been reviewed. Since a different approach is usually employed for the diastereoselective hydrogenation of different functional groups, the results will be discussed according to the type of functional group to be hydrogenated. In the majority of the reactions, palladium catalysts were used with success, and chiral amino acids, alcohols and amines were used as chiral auxiliaries. Hydrogenation reactions lead mainly to amino acids, amino acid derivatives and various amino compounds. We will present recent achievements in this area as well as some examples of diastereoselective hydrogenation, which lead to the formation of key intermediates for the synthesis of bioactive compounds.

\subsection{Diastereoselective hydrogenation of the $C=C$ bond}

The diastereoselective hydrogenation of the olefinic double bond has been well studied for $\alpha, \uparrow \beta$-dehydroaminoacid derivatives (1a, figure 1) over palladium, platinum oxide and Raney nickel catalysts. The hydrogenation of various $N$-acyl- $\alpha, \uparrow \beta$-dehydroaminoacid esters and amides usually gave low to moderate diastereoselectivity, with a de up to $40 \%$ [28-31]. A higher de $(68 \%)$ was obtained with $N$-acetyldehydrophenylalanyl coupled to the $(S)$-prolineanilide chiral auxiliary [32]. The best results were obtained with the $\alpha, \beta$-dehydroaminoacid structure (de up to $93 \%$ ) when

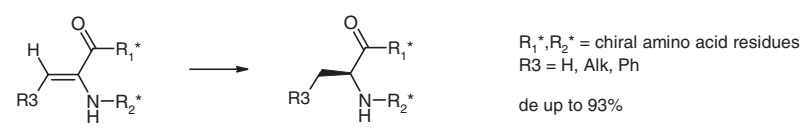

1a
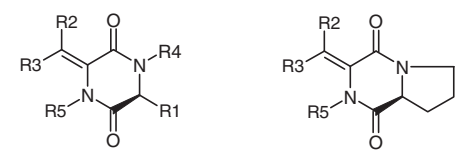

$\mathrm{R} 1=\mathrm{Al}$

R2 $=\mathrm{H}$, Alk, Ph

$\mathrm{R} 4, \mathrm{R} 5=$ protecting groups

de up to $93 \%$

$1 \mathrm{~b}$

$1 \mathrm{c}$
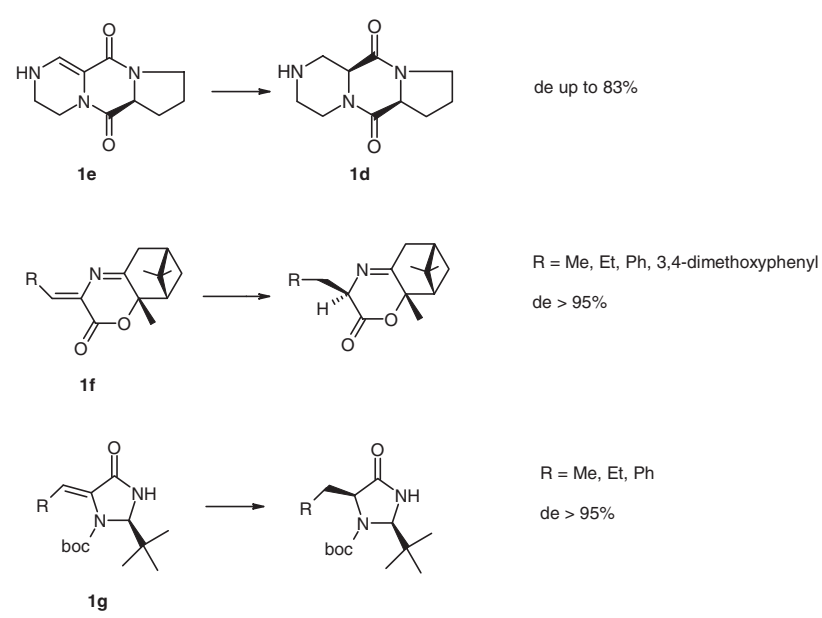

Figure 1. Structures of $\alpha, \beta$-dehydroaminoacids and diketopiperazine derivatives. 
chiral dehydrodipeptides, containing dehydroalanine and proline residues, were used [33].

In general, however, hydrogenation reactions of acyclic amino acid derivatives are not very selective [19]. Greater success was achieved by modifying dehydro-amino acids with a natural amino acid to give a rigid cyclic diketopiperazine structure (1b, figure 1). The diastereoselective hydrogenation of unsaturated diketopiperazine derivatives, which correspond to the cyclic $\alpha, \beta$-dehydrodipeptides (1b), has been studied by several groups [34-43], with the aim of developing a general method for the stereoselective synthesis of $\alpha$-amino acids. The chiral information was usually introduced by means of a natural amino acid and $(S)$ proline was often used to advantage as a chiral auxiliary (1c, figure 1). Palladium on charcoal was used most frequently as the catalyst and the resulting diastereoselectivity varied from 20 to $90 \%$. Deuteration experiments with substituted diketopiperazine $(\mathrm{R} 1=1$ methyl-ethyl, $\mathrm{R} 2=$ phenyl, $\mathrm{R} 3=\mathrm{H}$ ) with different protecting groups (R4 and R5) showed that the presence and type of the protecting group strongly influence the stereoselectivity of the reaction and that the diastereomeric excess can be reversed when a different protecting group is used [35].

Chiral diketopiperazines, corresponding to cyclic dipeptides, are of interest not only because they are an intermediate for chiral amino acids but also because they too exhibit a wide range of biological activity [44-46]. A large number of natural diketopiperazines contain a proline structure and the biological activity of this class of diketopiperazines varies considerably [47-51]. Our study of the diastereoselective hydrogenation of pyrazine derivatives [24], which is discussed in Section 2.5, revealed the stereoselective formation of a new diketopiperazine derivative (1d, figure 1). This molecule corresponds to a cyclic dipeptide and consists of one proteinogenic (L-proline) and one nonproteinogenic (piperazine- $(2 S)$-carboxylic acid) amino acid. The structure of this molecule has been described in detail [24]. Moreover, we found that the hydrogenation of the substrate, pyrazine-2-(methyl-(S)-prolinecarboxamide), proceeds via an unsaturated diketopiperazine derivative with the same structure as that of a cyclic $\alpha, \beta$ dehydrodipeptide (1e, figure 1). A separate study of the diastereoselective hydrogenation of this intermediate showed that a relatively high diastereoselectivity (de up to $83 \%$ ) is obtained over noble metal catalysts [52]. $\mathrm{Pd} / \mathrm{C}, \mathrm{Rh} / \mathrm{C}$ and $\mathrm{Ru} / \mathrm{C}$ were the most active and the most selective catalysts for this hydrogenation. This study also revealed the reaction course of hydrogenation of proline-modified pyrazine carboxylic acid, as will be discussed in Section 2.5 [24].

Almost complete diastereoselectivity (de $>95 \%$ ) was obtained in the hydrogenation of two other $\alpha, \beta$ dehydroamino acid derivatives (1f and 1g, figure 1) over a $\mathrm{Pd} / \mathrm{C}$ catalyst $[53,54]$. In the case of 1f, 2- hydroxypinan-3-one was used to advantage as chiral auxiliary and after a selective cleavage of the auxiliary, pure $(S)$-amino acid was obtained. Similarly, the hydrogenation product of $\mathbf{1 g}$ was hydrolyzed to obtain various nonproteinogenic amino acids. The high de obtained in these cases was probably due to the preferential adsorption from the unhindered side of the molecules. The examples shown in figure 1 demonstrate the importance of the effects of the structural and conformational properties of the substrates coupled with the chiral auxiliaries on the resulting diastereoselectivity.

The hydrogenation of more complex structures was also studied and the resulting diastereoselectivity differed depending on the structure of the substrate and the type of catalyst $[55,56]$. For example, the hydrogenation of spirotryprostatin B (2a, figure 2 ) over $\mathrm{Pd} / \mathrm{C}$ proceeded with more than $90 \%$ de, while the hydrogenation of the enamino bicyclic triaza compound ( $\mathbf{2 b}$, figure 2) carried out over $\mathrm{PtO}_{2}$ was completed with only $33 \%$ de.

Diastereoselective hydrogenation was also applied in the preparation of methyl (3S)-amino-3-(3-pyridyl)propanoate (3e, figure 3), a key starting material for the synthesis of an antagonist of the platelet fibrinogen receptor used to treat thrombosis [57]. ( $S$ )- $\alpha$-methylbenzylamine (3b), the chiral auxiliary, was coupled to nicotinoylacetate (3a) to form the chiral enamine (3c). The diastereoselective hydrogenation of enamine (3c) was carried out under various conditions; the best result ( $76 \%$ de) was obtained with the $\operatorname{Pd}(\mathrm{OH})_{2} / \mathrm{C}$ catalyst in a mixture of methanol and acetic acid under atmospheric pressure of hydrogen [56]. The desired product 3e was obtained as $\mathrm{HCl}$ salt by subsequent removal of the $\alpha$-methylbenzyl group by transfer hydrogenation with $\mathrm{Pd}(\mathrm{OH})_{2} / \mathrm{C}$ and 1,4-cyclohexadiene in acetic acid

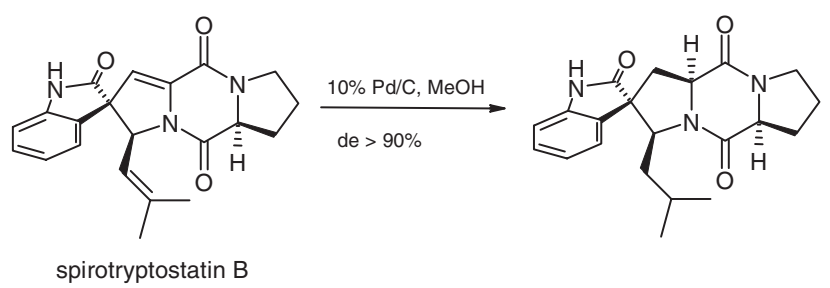

2a

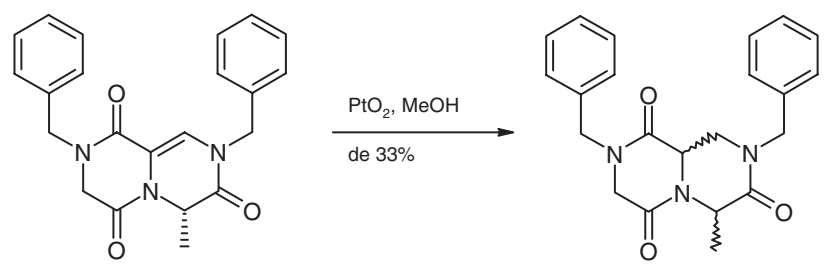

2b

Figure 2. Diastereoselective hydrogenation of $\mathrm{C}=\mathrm{C}$ bond in heterocycles. 


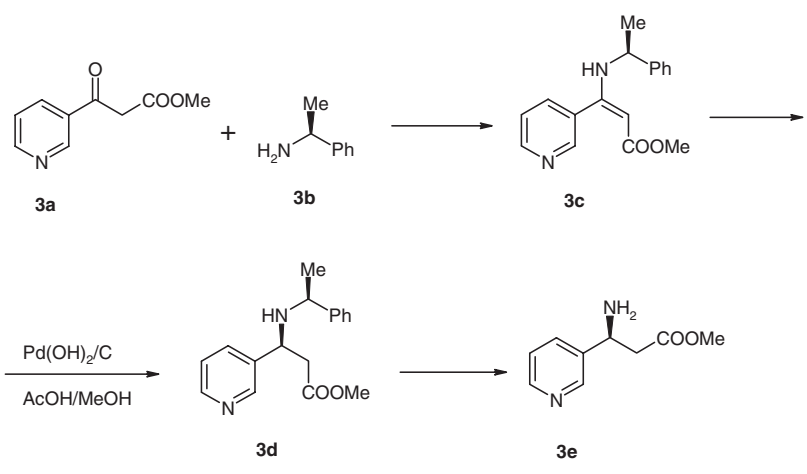

Figure 3. Synthesis of methyl (3S)-amino-3-(3-pyridyl)propanoate.

followed by recrystallization from methanol-ethylacetate solution.

High diastereoselectivity was obtained in the synthesis of $\left(2 S, 2^{\prime} R\right)$-erythro-methylphenidate (4c, figure 4), an isomer of threo-methylphenidate (Ritalin), which acts as stimulant of the nervous system and is used in the treatment of ADHD (attention deficit hyperactivity disorder) in children [57]. For this synthesis, (4S)phenyl-2-oxazolidine is used as the chiral auxiliary to control the diastereoselectivity in the hydrogenation of the enamine intermediate $(\mathbf{4 a})$. The reaction proceeded to the hydrogenated product $\mathbf{4 b}$ with very high diastereoselectivity (94\%). The desired product, $\left(2 S, 2^{\prime} R\right)$-erythro-methylphenidate $(\mathbf{4 c})$, was obtained after cleavage of the auxiliary by methanolysis with excellent enantiopurity. The opposite enantiomer of the chiral auxiliary gives $\left(2 R, 2^{\prime} S\right)$-erythro-methylphenidate [58].

\subsection{Diastereoselective hydrogenation of the $C=O$ bond}

The diastereoselective hydrogenation of the $\mathrm{C}=\mathrm{O}$ bond is applied less frequently than the hydrogenation of other functionalities. Nevertheless, several studies of the hydrogenation of $\alpha$-keto acid derivatives have been published [59-62]. Mitsui et al. studied the diastereoselective hydrogenation of the $\mathrm{C}=\mathrm{O}$ bond in $\alpha$-keto acids after converting the acid into an ester with an optically active alcohol (route I, figure 5) [59]. In a similar study, Harada and Munegumi coupled the acid

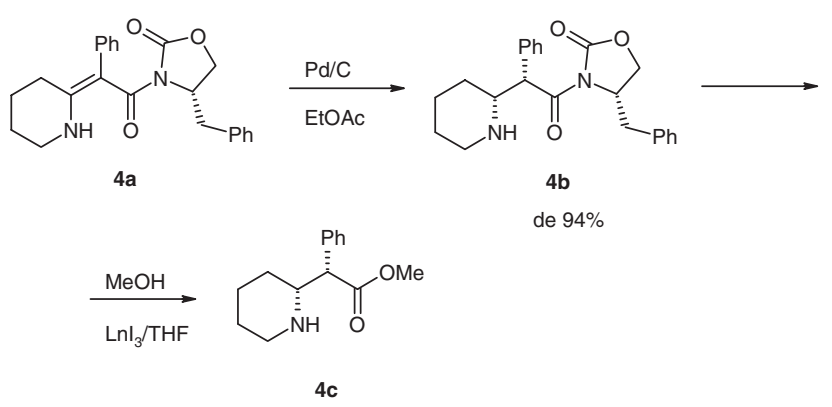

Figure 4. Diastereoselective synthesis of $\left(2 S, 2^{\prime} R\right)$-erythro-methylphenidate.

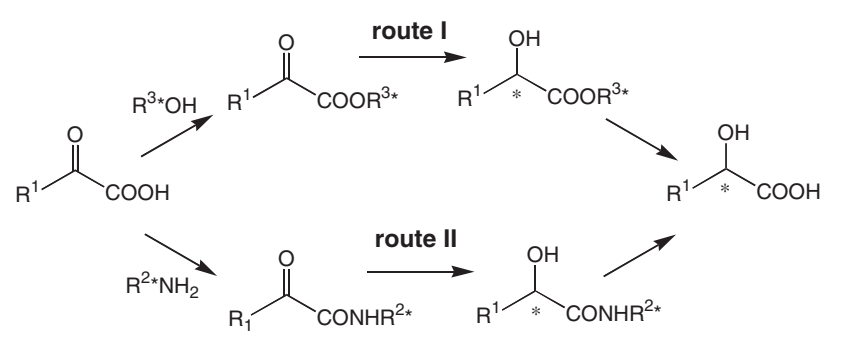

Figure 5. Diastereoselective hydrogenation of $\alpha$-keto acids using chiral amine (or amino acid derivative) and alcohol auxiliaries.

to an optically active amine [60] or an amino acid derivative [61] (route II, figure 5). The auxiliaries were cleaved after hydrogenation over palladium, either by acidic hydrolysis or by catalytic hydrogenolysis. This technique, for example, led to $75 \%$ diastereoselectivity in the hydrogenation of pyruvic acid with a prolinamide auxiliary [62].

\subsection{Diastereoselective hydrogenation of the $C=N$ bond}

Diastereoselective hydrogenation of the $\mathrm{C}=\mathrm{N}$ bond, formed by condensing amines with the $\mathrm{C}=\mathrm{O}$ bond of $\alpha$-keto acids, has been widely studied. Although there are several possibilities to diastereoselectively hydrogenate such a $\mathrm{C}=\mathrm{N}$ bond, the transamination technique has found widespread use. In this technique, the $\alpha$-keto acid (6a, figure 6) is derivatized with an optically active primary benzylic amine to form an imine. The imine is then hydrogenated over a heterogeneous catalyst, and the benzylic group is subsequently hydrogenolyzed over a palladium catalyst to give the amino acid product $(\mathbf{6 c})$. However, this method has the drawback of loosing the original chiral center on the benzylic amine because the amino group is transferred to the new amino acid product. Using this method, Hiskey and Northrop obtained a high diastereoselectivity (70-90\%) for many $\alpha$-keto acids with 1-phenylethylamine as the auxiliary [63]. This method is even more suitable for the synthesis of chiral amines (6d) from the corresponding ketones

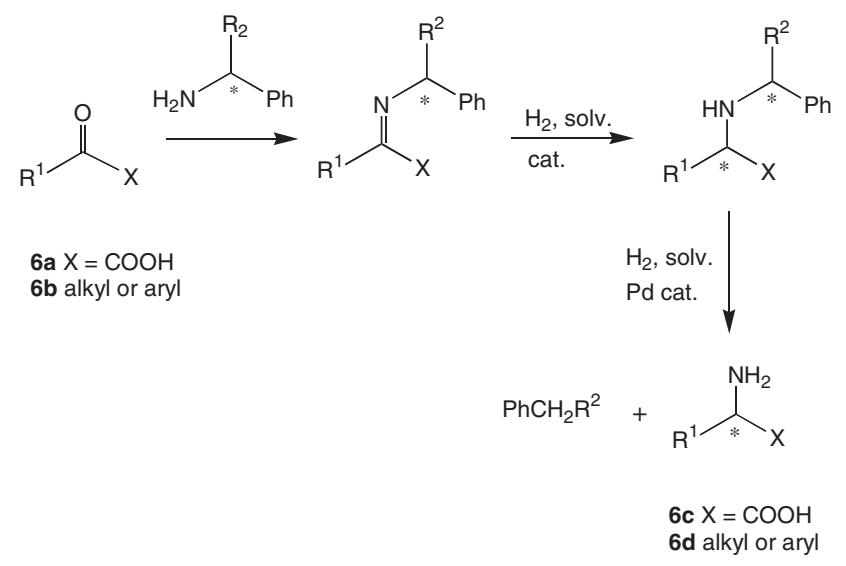

Figure 6. Diastereoselective hydrogenation of $\alpha$-keto acids and ketones using the transamination method. 
(6b). Using 1-phenylethylamine as the transamination agent, excellent diastereoselectivity $(>95 \%)$ was reported by Frahm et al. in the preparation of alicyclic primary amines from the corresponding alkanones [64,65]. The imine was reduced with a Raney nickel catalyst instead of a palladium catalyst because it resulted in higher selectivity. The transamination method was also successfully applied in the synthesis of various bioactive molecules, e.g., psychotomimetic phenylisopropylamines [66], derivatives of mescaline [67] and various amino acids $[68,69]$.

Bringmann and Geisler modified the transamination method also for the preparation of chiral benzylic amines substituted at the aromatic ring [70]. Their work was extended by Gutman et al. [71] who applied the transamination method in the asymmetric synthesis of $\alpha$-amino-substituted benzocyclic compounds (7a-c, figure 7). Their main interest was to prepare $(R)$ 1-aminoindane (7a), which is a key-intermediate in the synthesis of $(R)-N$-propargyl-1-aminoindan, a potent irreversible inhibitor of the $\mathrm{B}$ form of monoamine oxidase, which could be used in the treatment of Parkinson's disease [72,73]. The condensation of the appropriate ketone with 1-phenylethylamine led to the formation of an imine, which was diastereoselectively hydrogenated over $\mathrm{Pd} / \mathrm{C}$ to the secondary amine (de up to $86 \%$ ). The chiral auxiliary was then detached by debenzylation to give a primary amine [71].

Yamada et al. varied the transamination method, and condensed an $\alpha$-keto acid (8a) or a ketone (8b) with an optically active amino acid to give imines of types $\mathbf{8 c}$ and 8d (figure 8). Upon hydrogenation of these imines over a palladium catalyst and the removal of the auxiliary, the resulting amino acids and amines showed moderate diastereoselectivity $(50-85 \%)$ and a low chemical yield $[74,75]$.

Along with the hydrogenation of imines, similar to those prepared by Hiskey and Northrop, Harada and Matsumoto also studied the hydrogenation of other imino derivatives of $\alpha$-keto acids (9a and $\mathbf{9 b}$, figure 9) using amino acid ester auxiliaries $\left(\mathrm{R}^{2} * \mathrm{NH}_{2}\right)$ [76-78]. With a few exceptions, this approach gave diastereo-
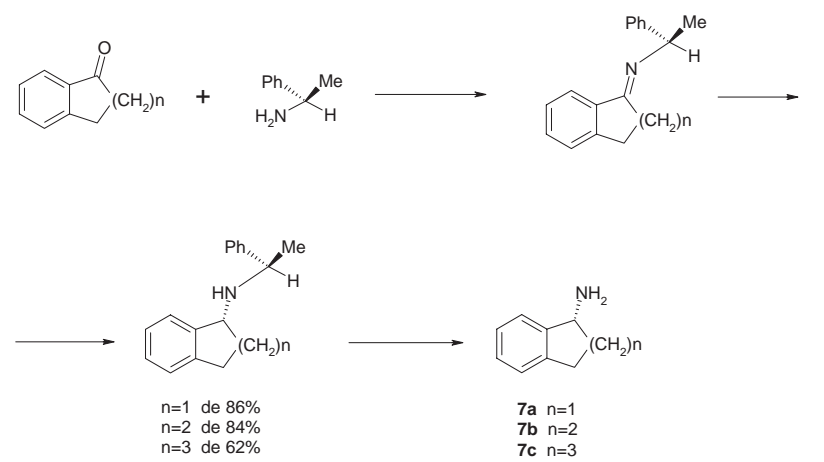

Figure 7. Asymmetric synthesis of $\alpha$-amino substituted benzocyclic compounds.

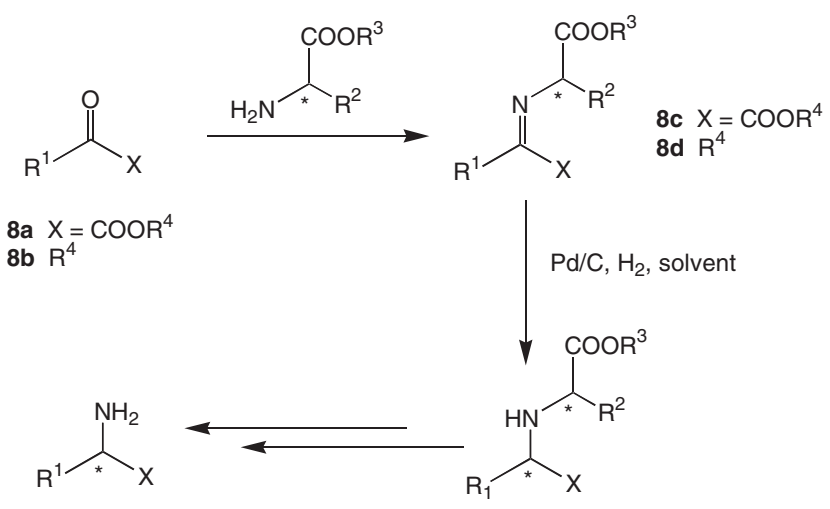

Figure 8. Diastereoselective hydrogenation of $\alpha$-keto acids and ketones using amino acid auxiliaries.

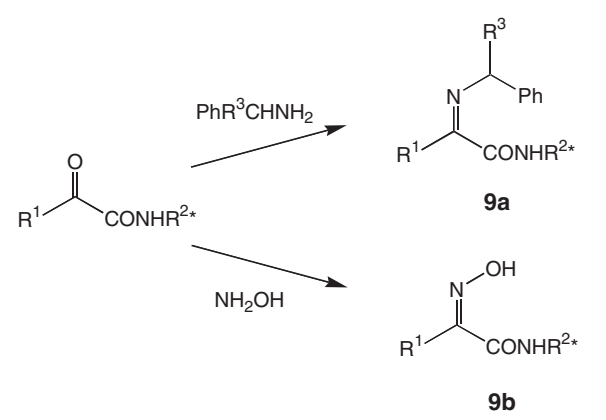

Figure 9. Diastereoselective hydrogenation of $\alpha$-keto acids investigated by Harada and Matsumoto.

selectivities below $50 \%$, probably because the center of chirality in the auxiliary was at a greater distance from the double bond, which underwent hydrogenation, than in the previous cases.

The diastereoselective hydrogenation of the $\mathrm{C}=\mathrm{N}$ bond was also applied for the synthesis of biologically active dipeptides. Thus, the ACE (angiotensin-converting enzyme) inhibitors, enalapril (10d) and lisinopril (10e), which are widely used to treat hypertension (figure 10), were successfully prepared by diastereoselective hydrogenation of an imine, which was obtained by the reductive amination of the $\alpha$-ketoacid derivative with the appropriate dipeptide (figure 10). In this case, the chiral auxiliary becomes a part of the desired molecule, with the result that the synthesis is easier because the chiral auxiliary does not have to be cleaved off. The first step in the synthesis is the formation of the dipeptide (10a). The dipeptide is then used for reductive amination of 2-oxo-4-phenylbutyrate (10b) to form the imine (10c), which is subsequently hydrogenated in one step. The best diastereoselectivity (SSS : RSS), 74\% for enalapril and $90 \%$ for lisinopril, was obtained using Raney nickel and ethanol as the solvent [21].

\subsection{Diastereoselective hydrogenation of substituted aromatics}

It is a well-known fact that the hydrogenation of many disubstituted aromatic compounds over hetero- 


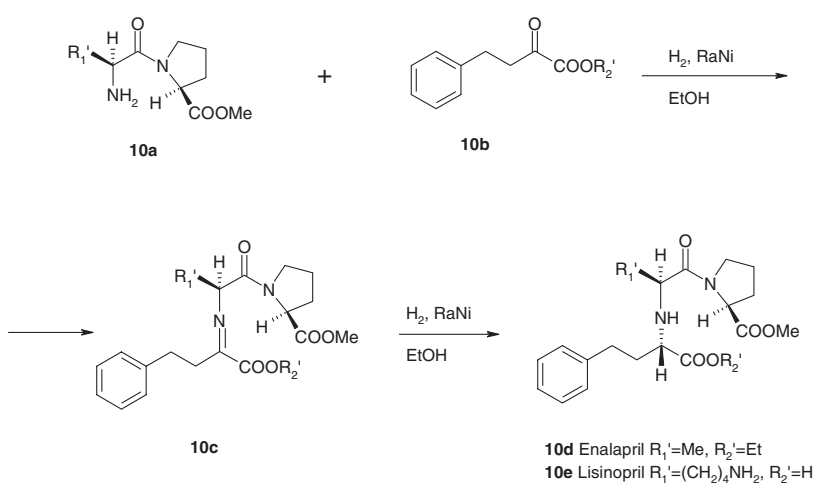

Figure 10. Diastereoselective synthesis of ACE inhibitors.

geneous catalysts in the liquid phase and under relatively mild reaction conditions yields the corresponding disubstituted cyclohexanes, primarily with the cis configuration. However, the selective synthesis of one of the two cis isomers by means of a chiral auxiliary is much more difficult [79]. Attempts to hydrogenate the aromatic ring diastereoselectively using heterogeneous catalysts gained momentum only recently and examples are given below. Almost all the investigations were conducted with ruthenium and rhodium catalysts, which are excellent for the hydrogenation of aromatic rings under moderate reaction conditions. With these catalysts, the nonreducible functional groups generally remain intact during the reaction [80-82].

Nasar et al. carried out the hydrogenation of 2methylanisole over colloidal rhodium modified by a chiral amine but the resulting enantioselectivity was very low $(\sim 1 \%)$ [83]. Owing to the poor selectivity of this system, they concentrated on diastereoselective hydrogenation. Thus, $O$-cresol was coupled to menthoxyacetic acid and camphanic acid (11a and 11b, figure 11). The diastereoselectivity obtained in the hydrogenation with these derivatives was $10 \%$ at best. Exl et al. attached vanillic acid to $(S)$-proline and menthol at the carboxyl group (11c and 11d) and to acetyl- $(S)$-proline at the hydroxyl group (11e). Hydrogenation of these derivatives gave a maximum de of about $6 \%$ [84].

Besson et al. made a thorough study of the diastereoselective hydrogenation of $o$-toluic acid coupled to many different types of proline auxiliaries [85-88]. Hydrogenation reactions were conducted at room temperature in alcoholic solvents and at 50 bar hydrogen pressure over either carbon- or aluminasupported rhodium catalysts. The yield of cis diastereomers exceeded $90 \%$ with all the catalysts and almost all the substrates. The addition of an amine modifier during the reaction changed the extent of diastereoselectivity. Table 1 lists the results obtained for a variety of substrates (12a-d) hydrogenated with and without an amine (figure 12).

With $\mathrm{Rh} / \mathrm{C}$ catalysts, selectivity to $\mathbf{1 2 e}$ was low upon hydrogenation in the absence of the amine (A,C,D, $, \mathbf{H}, \mathbf{J}$ in table 1). Increasing the concentration of the amine<smiles>Cc1ccccc1OC(=O)CO[C@H]1C[C@H](C)CC[C@H]1C(C)C</smiles>

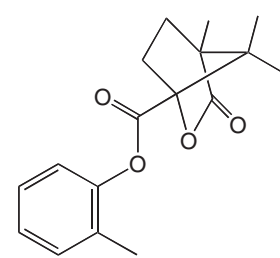

$11 b$

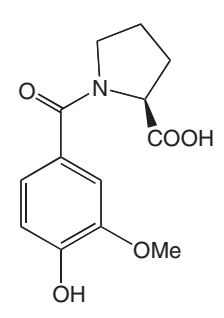

$11 \mathrm{c}$

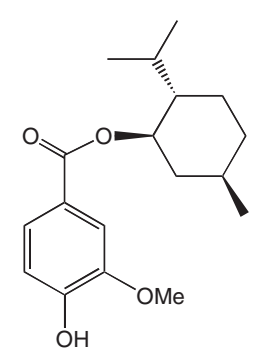

$11 d$

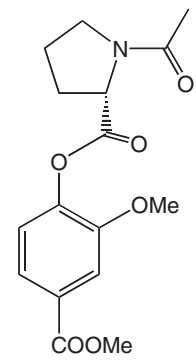

$11 \mathrm{e}$
Figure 11. Initial attempts of diastereoselective hydrogenation of aromatic compounds.

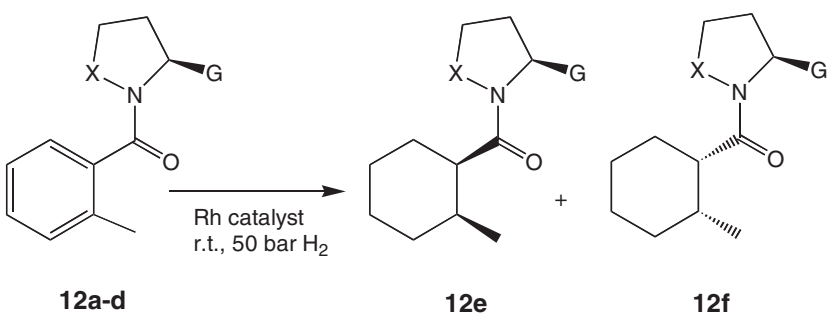

Figure 12. Substrates investigated by Besson et al.; for definitions of $\mathrm{X}$ and $\mathrm{G}$, see table 1 .

EDCA ( $N$-ethyl- $N, N$-dicyclohexylamine) resulted in a steady increase in the selectivity to the other diastereomer $\mathbf{1 2 f}$ and a steady decrease in the reaction rate. The increase in selectivity was not confined to the EDCA amine; a variety of amines, including primary and tertiary and even chiral amines, led to a very similar increase in selectivity. The effect of increasing the amineto-rhodium ratio was studied with two amine additives; the selectivity to $\mathbf{1 2 f}$ stabilized at an amine-to-rhodium molar ratio of 3.5. This was considered to be the optimum amine-to-rhodium ratio, since the addition of amine was detrimental to the activity of the catalyst. Thus, there was a significant increase in the diastereoselectivity of all the substrates when hydrogenation took place over the $\mathrm{Rh} / \mathrm{C}$ catalyst in a reaction mixture containing an amine (for e.g., $\mathbf{H}$ to I). In contrast, the alumina-supported rhodium catalyst was moderately selective to 12f, even without the addition of the amine (F). The selectivity of this catalyst to $\mathbf{1 2 f}$ increased further in the presence of the amine (F to $\mathbf{G}$ ). The diastereoselectivity did not change significantly when an isopropyl ester (12b) was used instead of the methyl ester (12a). However, changing the solvent from ethanol to 
Table 1

Results obtained in diastereoselective hydrogenation reactions investigated by Besson et al.

\begin{tabular}{|c|c|c|c|c|c|c|}
\hline Substrate & Catalyst & Solvent & Modifier & $\%$ de to $12 \mathrm{e}$ & Reference & Entry \\
\hline \multirow[t]{7}{*}{ 12a, $\mathrm{X}=\mathrm{CH}_{2}, \mathrm{G}=\mathrm{COOMe}$} & $\mathrm{Rh} / \mathrm{C}$ & $\mathrm{EtOH}$ & - & -17 & [85] & A \\
\hline & $\mathrm{Rh} / \mathrm{C}$ & $\mathrm{EtOH}$ & EDCA & 42 & [85] & B \\
\hline & $\mathrm{Rh} / \mathrm{C}$ & $\mathrm{MeOH}$ & - & -18 & [85] & $\mathbf{C}$ \\
\hline & $\mathrm{Rh} / \mathrm{C}$ & $i-\mathrm{PrOH}$ & - & -18 & {$[85]$} & D \\
\hline & $\mathrm{Rh} / \mathrm{C}$ & $i$-PrOH & EDCA & 26 & [85] & $\mathbf{E}$ \\
\hline & $\mathrm{Rh} / \mathrm{Al}_{2} \mathrm{O}_{3}$ & $\mathrm{EtOH}$ & - & 30 & [86] & $\mathbf{F}$ \\
\hline & $\mathrm{Rh} / \mathrm{Al}_{2} \mathrm{O}_{3}$ & $\mathrm{EtOH}$ & EDCA & 38 & [86] & G \\
\hline \multirow[t]{2}{*}{$\mathbf{1 2 b}, \mathrm{X}=\mathrm{CH}_{2}, \mathrm{G}=\mathrm{COO} i-\mathrm{Pr}$} & $\mathrm{Rh} / \mathrm{C}$ & $\mathrm{EtOH}$ & - & -24 & {$[85]$} & $\mathbf{H}$ \\
\hline & $\mathrm{Rh} / \mathrm{C}$ & $\mathrm{EtOH}$ & EDCA & 48 & [85] & I \\
\hline \multirow[t]{2}{*}{ 12c, $\mathrm{X}=\mathrm{CH}_{2}, \mathrm{G}=\mathrm{CONH} i-\mathrm{Pr}$} & $\mathrm{Rh} / \mathrm{C}$ & $\mathrm{MeOH}$ & - & -13 & [87] & $\mathbf{J}$ \\
\hline & $\mathrm{Rh} / \mathrm{C}$ & $\mathrm{MeOH}$ & DOCEA & 16 & [87] & $\mathbf{K}$ \\
\hline \multirow[t]{4}{*}{ 12d, $\mathrm{X}=\mathrm{CO}, \mathrm{G}=\mathrm{COOMe}$} & $\mathrm{Rh} / \mathrm{C}$ & $\mathrm{EtOH}$ & - & 35 & [88] & $\mathbf{L}$ \\
\hline & $\mathrm{Rh} / \mathrm{C}$ & $\mathrm{EtOH}$ & EDCA & 90 & [88] & $\mathbf{M}$ \\
\hline & $\mathrm{Rh} / \mathrm{Al}_{2} \mathrm{O}_{3}$ & $\mathrm{EtOH}$ & - & 90 & [88] & $\mathbf{N}$ \\
\hline & $\mathrm{Rh} / \mathrm{Al}_{2} \mathrm{O}_{3}$ & $\mathrm{EtOH}$ & EDCA & 95 & [88] & $\mathbf{O}$ \\
\hline
\end{tabular}

Note $:$ EDCA $=N$-ethyl- $N, N$-dicyclohexylamine; DOCEA $=N, N$-dioctyl- $N$-cyclohexylamine.

isopropanol resulted in a significant reduction in the diastereoselectivity of 12a, whereas methanol had almost no effect. Using an amide (12c) as the auxiliary instead of an ester (12b) gave lower selectivity.

A change in the hydrogen pressure during the reaction or a change in the dispersion of the catalyst had no effect on the diastereoselectivity obtained in the hydrogenation of 12a [89]. A detailed investigation of 12a indicated that a cyclohexene intermediate, which was not fully hydrogenated, formed during the hydrogenation of 12a with all the catalysts. The intermediate hydrogenated with a different diastereoselectivity to $\mathbf{1 2 e}$ / $12 f$ than the parent aromatic substrate [85]. The formation of the intermediate made it difficult to interpret the variation in the selectivity after the addition of the amine or after changing the solvent. Further complications arose because the substrate 12a may exist in two atropisomeric forms, which may hydrogenate with different diastereoselectivity [89]. In contrast, 12d was prepared selectively in one of its atropisomeric forms [88]. The excellent diastereoselectivity obtained in the hydrogenation of $\mathbf{1 2 d}$ over the alumina-supported catalyst $(\mathbf{N})$ was attributed to a stronger interaction of the substrate, with incompletely reduced rhodium, higher steric constraints owing to the flat morphology of rhodium particles and the interaction of the substrate with alumina upon adsorption [90].

Hydrogenation of 12a was conducted on ruthenium, palladium and platinum catalysts as well as on rhodium, but the performance of the former catalysts was much poorer than that of the rhodium catalysts [89]. The selectivity in the hydrogenation of $\mathbf{1 2 d}$ was high with the ruthenium catalyst and only slightly lower than that obtained with the rhodium catalysts [88].

Hydrogenation of other aromatic compounds-auxiliary moieties that have been investigated by Neto $[90,91]$ are shown in figure 13 . The methoxy group in 13a was partially hydrogenolyzed during the hydrogenation of the aromatic ring over the rhodium catalysts, and the hydrogenated product had a de up to $12 \%$. The hydrogenation of $\mathbf{1 3 b}$ did not proceed at room temperature over rhodium catalysts, probably because of the inhibiting effect of the amine; further investigations were not conducted. Using pantolactone as the chiral auxiliary (13c), a diastereoselectivity of $20 \%$ was obtained upon hydrogenation over an aluminasupported rhodium catalyst. Hydrogenation of $m$-toluic acid (13d), using the same auxiliary as in 12a, gave a diastereoselectivity of $35 \%$ with a $\mathrm{Rh} / \mathrm{C}$ catalyst in the presence of amine and a high yield of the trans products (cis: trans $=80: 20$ ).

Ranade et al. extended the studies of Besson et al. to other aromatic compounds [92-95]. Thus, the $(S)$ proline chiral auxiliary was used for the stereoselective hydrogenation of $o$-toluidine and the diastereoselective hydrogenation of $(S)$-proline-2-methylanilide was studied [92]. Two cis- and two trans-hydrogenated products as well as a cyclohexene intermediate were obtained with rhodium and ruthenium catalysts (figure 14); platinum and palladium catalysts were much less active. The cisto-trans ratio was usually between 4 and 5 . The two trans isomers were formed in almost equal amounts, i.e., without any diastereoselectivity. In the case of the cis isomers, the $1 R, 2 S$ isomer was always obtained in excess when $(S)$-proline was used as the chiral auxiliary, while with $(R)$-proline, the $1 S, 2 R$ diastereomer was formed in excess. This demonstrates that the proline auxiliary is responsible for the chiral induction in the hydrogenation reaction. The same de, but with the opposite sign, was obtained with $(S)$-proline and $(R)$-proline. Thus, the top two structures of $(R)$-proline-2-methylanilide and $(S)$ proline-2-methylanilide shown in figure 15 seem to adsorb on the rhodium surface and result in the formation of the diastereomers $R^{\prime}, 1 S, 2 R$ and 
<smiles>COc1ccccc1C(=O)N1CCC[C@H]1CO</smiles>

$13 a$<smiles>Cc1ccccc1C(=O)O[C@H]1C(=O)OCC1(C)C</smiles>

$13 c$<smiles>Cc1ccccc1C(=O)N1CCC[C@H]1CN1CCCC1</smiles>

$13 b$<smiles>CC(=O)[C@H]1CCCN1C(=O)c1cccc(C)c1</smiles>

13d
Figure 13. Substrates investigated by Neto.

$S^{\prime}, 1 R, 2 S$, respectively, when hydrogen is added from the metal face of the rhodium catalyst. The nitrogen atom of the proline and the aromatic rings of these two structures lie in the same plane on the catalyst surface, and the amide bond is almost parallel to the surface of the catalyst. The other cis diastereomers, namely $S^{\prime}, 1 S, 2 R$ and $R^{\prime}, 1 R, 2 S$, are formed when the adsorption through the benzene ring takes place from its opposite face (the lower two structures in figure 15). However, these configurations lead to more steric crowding because of the interaction of the methyl group with the carbonyl group, thus making them less favorable structures. Partial hydrogenation of a substituted aromatic ring leads to the formation of cyclohexene derivatives, which are responsible for the formation of trans isomers.

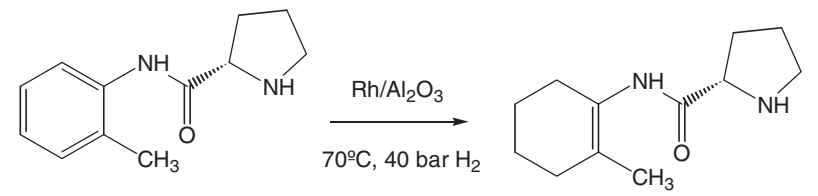

Cyclohexenic Intermediate*
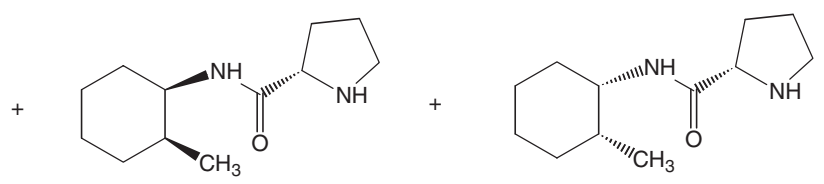

$1 R, 2 S$ cis diastereomer

$1 S, 2 R$ cis diastereomer<smiles>C[C@@H]1CCCC[C@H]1NC(=O)[C@@H]1CCCN1</smiles>

$1 R, 2 R$ trans diastereomer

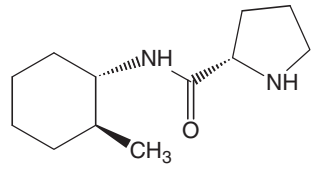

$1 S, 2 S$ trans diastereomer

Figure 14. Hydrogenation of $(S)$-proline-2-methylanilide (*the position of the double bond in the cyclohexene intermediate is not known).

Kinetic data of the reaction indicated that the cyclohexene intermediate was hydrogenated at the same time as the substrate and, in a standard experiment, reached a maximum concentration up to $8 \%$ of the initial concentration of the reactant [92]. The de increased gradually with the conversion of the substrate and usually reached 45 to $55 \%$ with the rhodium catalysts. The diastereoselectivity obtained with the ruthenium catalyst was lower (around 10\% de). The stereoselectivity seems to depend strongly on the substrate, on the type of the metal catalyst and, to a lesser extent, on other factors. Relatively small differences were observed among the rhodium catalysts prepared from different precursors on different supports and under different reaction conditions. The hydrogenation activity, however, is dependent on the temperature, the catalyst precursor, the support and the solvent. The substrate adsorbs preferentially through the amine group and the diastereoselectivity arises from adsorption of the substrate on a rhodium surface, preferentially through one of the two diastereotopic faces of the aromatic ring.

The effect of the structure of the chirally modified aromatic compound on the diastereoselectivity was also demonstrated in the diastereoselective hydrogenation of
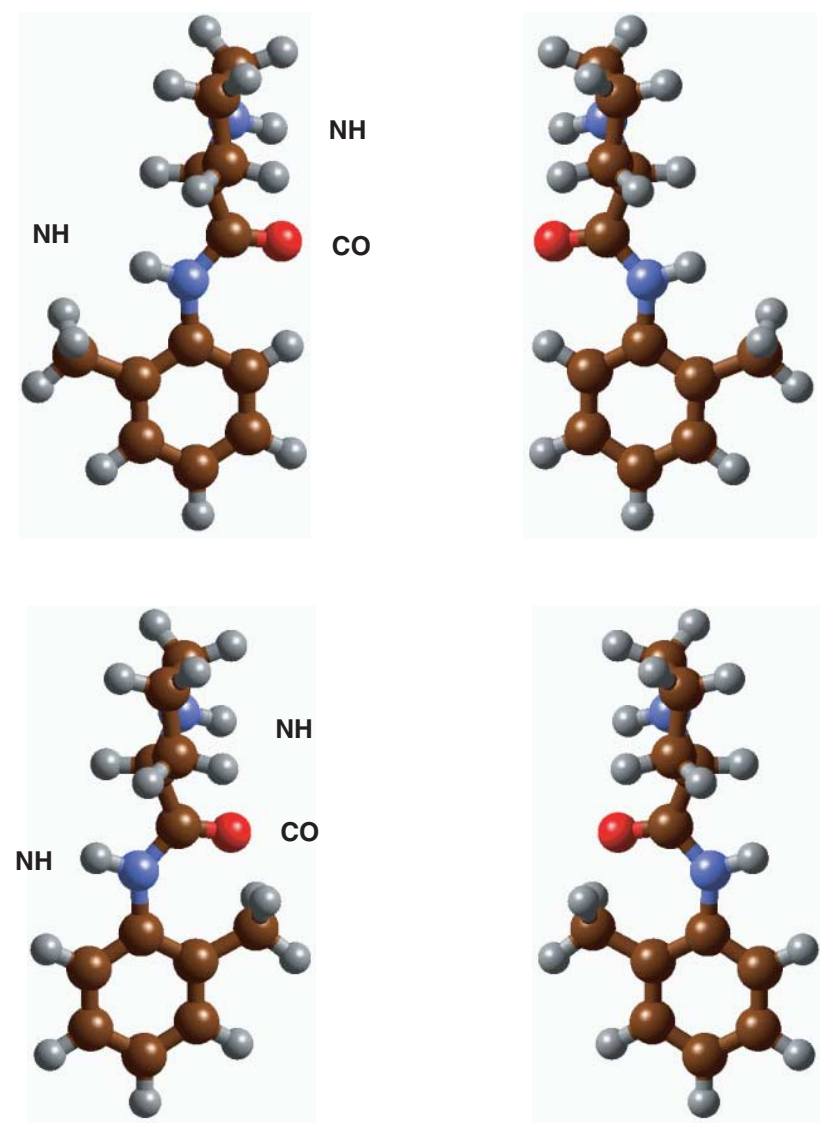

Figure 15. Top views of the structures of proline-2-methylanilide adsorbed on a metal surface. From top, clockwise, formation of $R^{\prime}, 1 S, 2 R ; S^{\prime}, 1 R, 2 S ; S^{\prime}, 1 S, 2 R$, and $R^{\prime}, 1 R, 2 S$. 
(S)-proline-modified anthranilic acid (figure 16) [93]. The hydrogenation led to the simultaneous formation of the fully hydrogenated cis products and of a cyclohexene by-product. Very small amounts of fully hydrogenated trans products were obtained. The ratio between the $c i s$ and trans isomers was in the range of 15 to 30 . The typical yield of the cis diastereomers together was 30 to $40 \%$ and that of the cyclohexene by-product was 60 to $70 \%$. The $(5 \mathrm{a} R, 9 \mathrm{a} S)$-diastereomer was always obtained in excess upon direct hydrogenation of the reactant. The chemoselectivity is reported as the selectivity to the two cis diastereomers, while the diastereoselectivity is reported as the diastereomeric excess between the cis diastereomers. The activity of the platinum and palladium catalysts was low in this hydrogenation, and more attention was therefore paid to the rhodium and ruthenium catalysts supported on charcoal and alumina. Ru-based catalysts gave a higher yield of cis products than $\mathrm{Rh}$ catalysts but exhibited a lower diastereoselectivity (de up to $83 \%$ compared to a de up to $94 \%$ with rhodium). When alumina was used as the support for $\mathrm{Rh}$ and $\mathrm{Ru}$, the diastereoselectivity was higher than with charcoal. With the alumina-supported catalysts, the chemoselectivity and diastereoselectivity varied only slightly with the conversion. For the carbon-supported catalysts, however, the chemoselectivity increased and the diastereoselectivity decreased with conversion. To explain the dependence of diastereoselectivity on conversion, the cyclohexene by-product was isolated and further hydrogenated with the $\mathrm{Rh} / \mathrm{C}, \mathrm{Rh} / \mathrm{Al}_{2} \mathrm{O}_{3}$ and $\mathrm{Ru} / \mathrm{C}$ catalysts under the same reaction conditions as for the hydrogenation of the reactant. A lower substrate-tocatalyst ratio was used because the hydrogenation of the
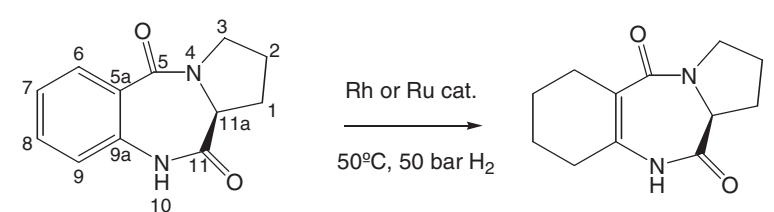

Cyclohexene by-product

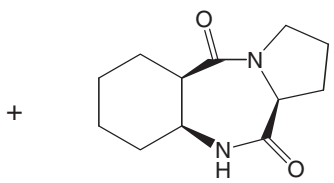

$5 \mathrm{a} R, 9 \mathrm{aS}$ cis diastereomer

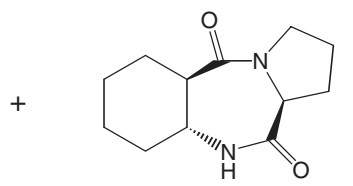

$5 \mathrm{a} R, 9 \mathrm{a} R$ trans diastereomer

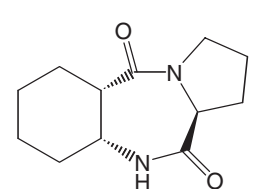

$5 \mathrm{a} S, 9 \mathrm{a} R$ cis diastereomer

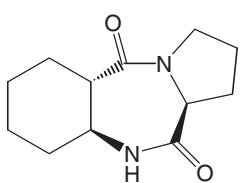

$5 \mathrm{aS}, 9 \mathrm{aS}$ trans diastereomer
Figure 16. Hydrogenation products of $(S)$-proline-modified anthranilic acid. cyclohexene by-product occurred at a much slower rate than that of the substrate. The activity over the $\mathrm{Rh} / \mathrm{Al}_{2} \mathrm{O}_{3}$ catalyst was negligible, while over $\mathrm{Ru} / \mathrm{C}$, hydrogenation proceeded at a moderate rate but not to complete conversion. $\mathrm{Rh} / \mathrm{C}$ was slightly more active than $\mathrm{Rh} / \mathrm{Al}_{2} \mathrm{O}_{3}$ but significantly less active than $\mathrm{Ru} / \mathrm{C}$. Hydrogenation of the cyclohexene by-product yielded predominantly cis diastereomers with carbon-supported catalysts. However, there was an inversion in the diastereoselectivity, and the $(5 \mathrm{a} S, 9 \mathrm{a} R)$-cis-diastereomer was obtained as the major product with a de of about $30 \%$ for $\mathrm{Ru} / \mathrm{C}$ and about $40 \%$ for the $\mathrm{Rh} / \mathrm{C}$ catalyst. Thus, the subsequent hydrogenation of the cyclohexene by-product on carbon-supported catalysts accounts for the dependence of diastereoselectivity on conversion and for their low overall de.

The hydrogenation of the cyclohexene by-product was facilitated when water was used as the solvent [93]. This explains the low overall de and the high yield of cis products when water is the solvent as opposed to ethanol, especially with carbon-supported catalysts. The reason for the very slow hydrogenation of the byproduct, even when a powerful hydrogenating catalyst such as $\mathrm{Rh}$ is employed, is probably the inability of the olefinic carbon atoms to coordinate with the metal surface due to electronic or steric effects. In the case of alumina-supported catalysts, preferential adsorption of the by-product on the alumina surface via the polar amide groups may account for their inactivity. The alumina-supported catalysts exhibited a lower activity than the carbon-supported catalysts in the hydrogenation reactions, probably due to a similar preferential adsorption on the alumina support.

The diastereoselectivity obtained in the hydrogenation reactions is the result of the preferential reactivity of one of its two diastereotopic faces on the surface of the catalyst. Surprisingly, if only steric factors determine the face, upon which the substrate adsorbs on the sur-face of the catalyst, molecular modeling (using the MM2 force field in MacroModel) suggests that the $(5 \mathrm{a} S, 9 \mathrm{a} R)$-diastereomer (figure 16) is the major product. The structure of the reactant molecule was also confirmed by means of the Cerius ${ }^{2}$ programme and is similar to the crystal structure determined by Feigel $e t$ al. [96]. The NMR spectrum does not change between -100 and $120^{\circ} \mathrm{C}$, suggesting that its conformation is homogeneous in the $\mathrm{CDCl}_{3}$ solution. The diastereoselectivity in the hydrogenation reaction seems to be the result of the electronic interactions of its amide bonds with the surface of the catalyst. These electronic interactions are probably weaker with $\mathrm{Ru}$ than with $\mathrm{Rh}$, which would explain why $\mathrm{Ru}$ catalysts are less selective.

The diastereoselective hydrogenation of $(S)$-prolinemodified anthranilic acid shows that a high diastereoselectivity can be obtained when a more rigid structure, such as the anthranilic acid-proline moiety, is used. 
Unfortunately, the high diastereoselectivity is detrimental to the low chemoselectivity because the further hydrogenation of the cyclohexene by-product proceeds with the opposite de.

The results obtained during the hydrogenation of $(S)$-proline-2-methylanilide and $(S)$-proline-modified anthranilic acid demonstrated the importance of the conformational rigidity of the aromatic compoundauxiliary adduct for attaining a high stereoselectivity during hydrogenation. The significance of the steric requirements of the substrate molecule in diastereoselective hydrogenation was also illustrated with a series of monosubstituted indane and tetralin compounds. The influence of various functional groups on diastereoselectivity was studied on rhodium catalysts in detail [94,95] and it revealed that the facial selection in the diastereoselective hydrogenation of aromatics is primarily determined by the steric requirements of the molecule. The electronic interaction played an important role only when the molecule contained an amino group or when the hydrogenation was conducted in the presence of inorganic basic additives.

The diastereoselective hydrogenation of substituted aromatics was also successfully applied in the synthesis of intermediates for pharmaceuticals. An example of such an industrial application is the synthesis of $(3 S$, $4 \mathrm{a} S, 8 \mathrm{a} S)-N$-( $t$-butyl)decahydro-3-isoquinolinecarboxamide (figure 17), a key-intermediate in the synthesis of HIV-protease inhibitors (e.g. Saquinavir) and of antagonists of the excitatory amino acid receptors [22,23]. In this case, the chiral auxiliary is also part of the final molecule. The chiral information is introduced by proteinogenic amino acid, L-phenylalanine, which is transformed to tetrahydroisoquinoline- $N$ - $t$-butylcarboxamide in three steps. The next step is the diastereoselective hydrogenation of the tetrahydroisoquinoline moiety to the decahydroisoquinoline moiety. Two new chiral centers are formed during this reaction, which means that four different stereoisomers can originate from the reaction. Fortunately, the configuration on carbon- 3 and, thus, the orientation of the carboxyamide group as well as the choice of the right catalyst favor the formation of only one stereoisomer (figure 17). The highest diastereoselectivity (about 94\%) was obtained with a ruthenium catalyst supported on active carbon. However, the diastereoselectivity obtained with rhodium was also around $90 \%$. The structure of Saquinavir shows how the decahydroquinoline moiety is employed in the final drug (figure 17). This example shows that nitrogen-containing heterocycles are very common components in a number of pharmaceuticals. Therefore, the diastereoselective hydrogenation of substituted heteroaromatics is of interest and is discussed in detail below.

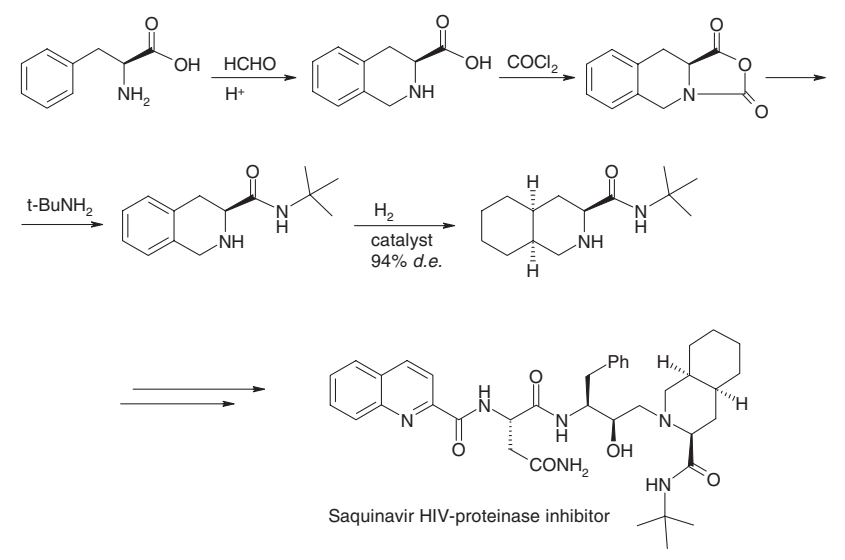

Figure 17. Synthesis of $(3 S, 4 \mathrm{a} S, 8 \mathrm{a} S)-N$-( $t$-butyl)decahydro-3-isoquinolinecarboxamide.

\subsection{Diastereoselective hydrogenation of substituted heteroaromatics}

Many biologically active molecules contain chiral heterocyclic components, which can be prepared by stereoselective catalytic hydrogenation of the corresponding substituted aromatic compounds. First attempts at hydrogenating aromatic $N$-containing heterocycles diastereoselectively were carried out by Tungler et al. [97,98]. They hydrogenated pyridine and pyrrole derivatives using noble metal catalysts $(\mathrm{Pd}, \mathrm{Rh}$, $\mathrm{Ru}$ and $\mathrm{Pt}$ ) and $(S)$-proline methylester as the chiral auxiliary (figure 18). The diastereoselectivity obtained in the hydrogenation of picolinic and nicotinic acids modified with $(S)$-proline methylester was relatively high. For example, the hydrogenation of $N-(\alpha)$-picolinoyl-(S)-proline methylester (18a) over $\mathrm{Pd} / \mathrm{C}$ resulted in $79 \%$ de and the hydrogenation of $N$-nicotinoyl- $(S)$ proline methylester (18b) in $94 \%$ de. However, other research groups could not reproduce these results, and recently, the authors reported lower diastereoselectivities $(<30 \%)$ [reference 13 in 99]. While palladium catalysts displayed the highest activity and the highest diastereoselectivity in the hydrogenation of the pyridine ring, better results were obtained with a rhodium catalyst (de of up to $95 \%$ ) in the hydrogenation of the pyrrole derivative $N$-(1'-methylpyrrole-2'-acetyl)-(S)proline methylester (18c). Temperature had a strong effect on diastereoselectivity, while the reaction solvent affected the reaction rate only.

Douja et al. recently published the results of diastereoselective hydrogenation of 2-methylnicotinic acid (19a, figure 19) bonded to different chiral aux-

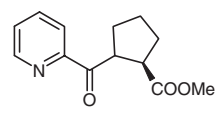

$18 a$

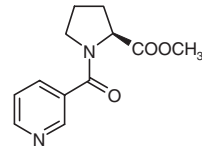

$18 b$

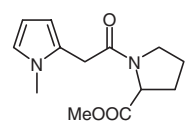

$18 \mathrm{c}$
Figure 18. Substrates hydrogenated by Tungler et al. 
iliaries [99]. The auxiliaries tested (methyl prolinate, methyl pyroglutamate, pantolactone, prolinol and methoxymethylpyrollidine) were similar to those used in the hydrogenation of $o$-toluic acid derivatives. They found that the reaction proceeds via intermediate 19b and that cis isomers $19 \mathrm{c}$ and $\mathbf{1 9 d}$ are formed predominantly. The reactions proceeded with moderate diastereoselectivity (up to $35 \%$ ) and the effect of the chiral auxiliary on de was not as strong as for $o$-toluic derivatives. Rhodium and ruthenium catalysts were effective in this hydrogenation, while the palladium catalyst was less active and had a lower de. A strong dependence of de on temperature was observed for the carbon-supported catalysts (de decreased from 18 to $10 \%$ as the temperature increased from 25 to $100^{\circ} \mathrm{C}$ but not for the alumina-supported catalysts) [99]. The solvent had a similar effect on the reaction rate and on the de, as in the hydrogenation of pyrrole derivatives [98].

These promising results led us to investigate the diastereoselective hydrogenation of pyrazine derivatives. The hydrogenation of the pyrazine ring produces various piperazine derivatives, which are of interest because they are used in many pharmacologically active compounds. Particular attention has been paid to the molecule of piperazine-(2S)-carboxylic acid [100], because it is widely used as a chiral-building block in the synthesis of many pharmaceuticals [101-106]. We studied the diastereoselective hydrogenation of pyrazine-2-carboxylic acid, modified by the proline auxiliary over various heterogeneous noble metal catalysts, as an alternative method for the preparation of piperazine(2S)-carboxylic acid [24]. The reaction scheme of the stereoselective preparation of piperazine-( $2 S)$-carboxylic acid (20a) is shown in figure 20. The first step in the synthesis was the coupling of pyrazine-2-carboxylic acid (20b) with the chiral auxiliary $(S)$-proline methylester (20c) to form pyrazine-2-(methyl- $(S)$-prolinecarbox-
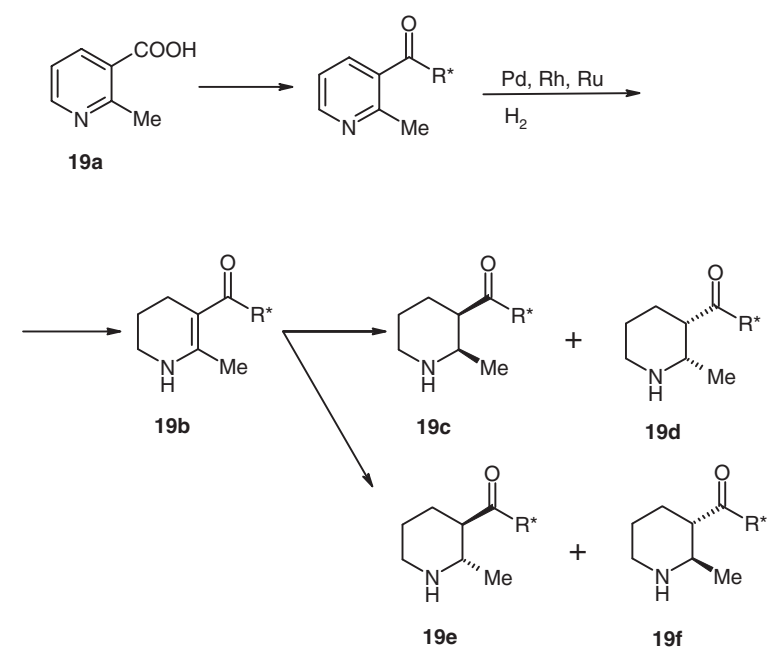

Figure 19. Diastereoselective hydrogenation of 2-methylnicotinic acid derivatives. amide) (20d). The diastereoselective hydrogenation of (20d) was studied using noble metal catalysts (Pd, Pt, Rh and $\mathrm{Ru}$ ) supported on different supports. The reaction proceeds via the partially hydrogenated intermediate (20e) to a mixture of saturated diastereomers (20f and 20g) (figure 20). The intermediate was formed by the intramolecular $\mathrm{N}$-acylation of the partially hydrogenated substrate. The intramolecular cyclization was probably very fast, because neither a partially hydrogenated substrate nor a noncyclic saturated product formed. The main products of the total hydrogenation were two diastereomers: $(4 \mathrm{a} S, 9 \mathrm{a} S)$ - and $(4 \mathrm{a} R, 9 \mathrm{a} S)$ octahydro-3a,6,8a-triaza-cyclopenta[b]naph-thalene4,9-dione (20f and 20g). The diastereomer $20 \mathrm{f}$ with the $(4 \mathrm{a} S, 9 \mathrm{a} S)$-configuration was formed in excess.

The most active catalyst was $10 \% \mathrm{Pd} / \mathrm{C}$, with which the highest content of the intermediate $(75 \%)$ as well as the highest diastereoselectivity $(67 \%$ in methanol and $79 \%$ in water) were reached. The activity, the maximum concentration of the intermediate and the diastereoselectivity were considerably lower with the other catalysts. The results show that there is a relationship between the final diastereoselectivity and the maximum concentration of the intermediate. The higher the concentration of the intermediate during the reaction the higher the diastereoselectivity. This was to be expected, because the structure of the cyclic intermediate is much more rigid than that of the substrate molecule. Therefore, the adsorption of the intermediate from one of its two diastereotopic faces on the catalyst is preferred and, thus, the formation of only one diastereomer is favored. Moreover, the course of the reaction and the development of diastereoselectivity during the reaction over the palladium catalyst (figure 21) revealed that the diastereoselectivity increases with the conversion of the substrate and then remains constant. A possible explanation is that this is caused by the total hydrogenation of the substrate followed by fast cyclization of the saturated product, which proceeds with a lower de
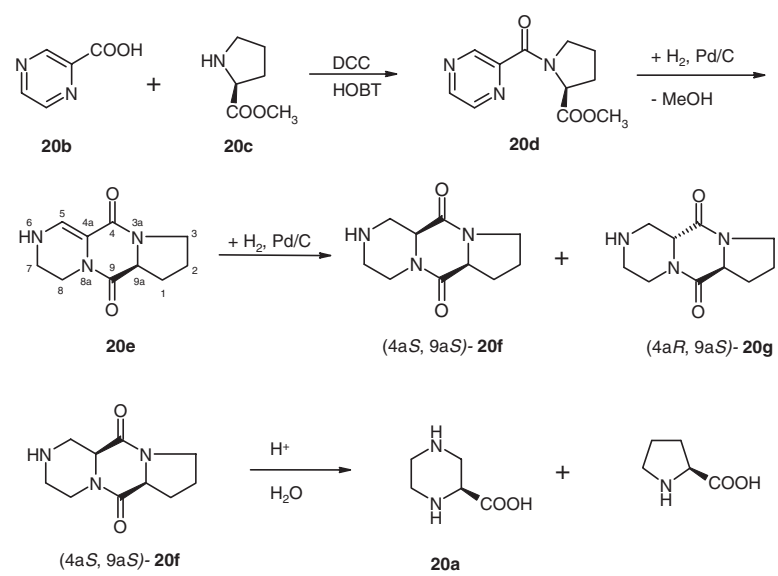

Figure 20. Reaction scheme of the preparation of piperazine-(2S)carboxylic acid. 
and can occur at the beginning of the reaction. To investigate the mechanism of the hydrogenation of pyrazine-2-(methyl- $(S)$-prolinecarboxamide) the unsaturated diketopiperazine intermediate (20e) was isolated from the reaction mixture and its hydrogenation was studied separately [52]. Higher diastereoselectivities (e.g., $79 \%$ in methanol with $\mathrm{Pd} / \mathrm{C}$ ) and slower reaction rates were obtained in the hydrogenation of the diketopiperazine intermediate (20e) under the same reaction conditions when the same noble metal catalysts were used. Although the reaction rate and the diastereoselectivity during the hydrogenation of pyrazine derivative (20d) over $\mathrm{Pd} / \mathrm{C}$ catalyst were considerably higher than over the other catalysts, similar reaction rates and diastereoselectivities were obtained with $\mathrm{Pd} / \mathrm{C}$, $\mathrm{Rh} / \mathrm{C}$ and $\mathrm{Ru} / \mathrm{C}$ during the hydrogenation of the intermediate $(\mathbf{2 0 e})$. Therefore, the cyclization reaction on the palladium catalyst seems to be much faster than on the other catalysts, and the greater molecular rigidity of the dehydrodipeptide intermediate (20e) seems to facilitate the differentiation of the two diastereotopic faces on the metal surface of the catalyst and thus increases diastereoselectivity. These findings also explain the relationship between the maximum concentration of the diketopiperazine intermediate (20e) and the diastereoselectivity and the dependence of the de on the conversion of the substrate (20d).

The influence of the reaction conditions on diastereoselectivity during the hydrogenation of pyrazine-2(methyl-( $S$ )-prolinecarboxamide) was studied as well [24]. A change in the reaction temperature (between 50 and $85^{\circ} \mathrm{C}$ ) had a considerable effect on the reaction rate but not on diastereoselectivity. This is probably due to the high conformational stability of the intermediate in this temperature range. Hydrogen pressure had a similar effect. No significant changes in diastereoselectivity were observed between 5 and $10 \mathrm{MPa}$, and the higher hydrogen pressure resulted only in a higher reaction rate. The type of solvent mostly affected the turn over

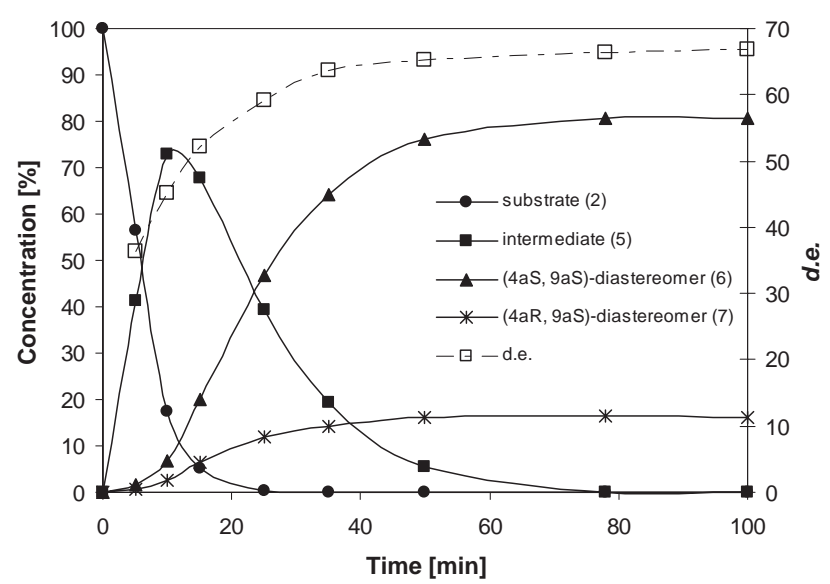

Figure 21. Reaction course of pyrazine-2-(methyl-( $S$ )-prolinecarboxamide) hydrogenation, catalyst: $10 \% \mathrm{Pd} / \mathrm{C}$, solvent methanol, $T=$ $80^{\circ} \mathrm{C}, \mathrm{p}\left(\mathrm{H}_{2}\right)=8 \mathrm{MPa}$, de $67 \%$. frequency (TOF) of the reaction and the formation of the diketopiperazine intermediate. There were only slight variations in diastereoselectivity with the different solvents. The reaction rate was lower for solvents with a lower polarity. This may be due not only to the lower hydrogenation activity but also to the lower rate of intramolecular cyclization, which is influenced by the reaction medium. Protic solvents such as water facilitate the intramolecular cyclization of the substrate by the protonation of the carbonyl group of the proline auxiliary. Therefore, the maximum content of the intermediate was higher with solvents of higher polarity. The highest reaction rate as well as the highest diastereoselectivity were obtained with water.

As mentioned above, the aim of the diastereoselective hydrogenation of pyrazine-2-carboxylic acid was the stereoselective synthesis of piperazine-(2S)-carboxylic acid. The diastereoselective hydrogenation of $(S)$-proline-modified pyrazine-2-carboxylic acid resulted in the formation of the diketopiperazine derivative (20f) with a maximum de of $79 \%$ (i.e., almost $90 \%$ of desired diastereomer in the reaction product). The diketopiperazine diastereomers were separated by crystallization and the diketopiperazine ring was cleaved by acidic hydrolysis without racemization. After the cleavage, the hydrochlorides of piperazine-(2S)-carboxylic acid (20a) and $(S)$-proline were obtained (figure 20). This procedure has several advantages over homogeneous catalytic hydrogenation (the heterogeneous catalyst is inexpensive and easy to separate, and there are fewer reaction steps) but can hardly compete with fractional crystallization of the diastereomeric salts of the racemic piperazine-2-carboxylic acid. However, this example clearly demonstrates that the diastereoselective hydrogenation of more rigid structures, such as a tricyclic dehydrodiketopiperazine intermediate (20e), proceeds with high diastereofacial selectivity.

\section{General aspects and trends in diastereoselective hydrogenation}

This review summarizes results of academic as well as industrial research. Industrial diastereoselective hydrogenation focuses on target molecules, while academic research tends to focus on general aspects and mechanisms of diastereoselective hydrogenation. Results of industrial research are usually published only after a filing of a patent, that is, only after success has been achieved. This review demonstrates that heterogeneous diastereoselective hydrogenation is a useful tool for the stereoselective preparation of fine chemicals. The main advantages of heterogeneous catalysts are that they are much cheaper and are easier to handle than homogeneous catalysts. Inexpensive natural compounds often serve as the chiral auxiliaries in the diastereoselective hydrogenation and can usually be recycled or end up as 
part of the final product. Thus, the price of the auxiliary is not a consideration.

One of the most important issues to be addressed is the diastereomeric excess obtained during the reaction, the key factor being the conformational rigidity and steric arrangement of the substrate molecule. The rigid ring structures, which can adsorb on the metal surface of a heterogeneous catalyst from only one of their diastereotopic faces, usually give higher diastereoselectivity. Thus, the rigid molecules, such as $\alpha, \beta$-dehydroamino acid derivatives and various unsaturated diketopiperazine derivatives, give a higher de. It is difficult to draw a general conclusion about the diastereoselectivity of the hydrogenation of different functional groups. Some of the results show that the hydrogenation of isolated $\mathrm{C}=\mathrm{C}$ and $\mathrm{C}=\mathrm{N}$ bonds may lead to very high diastereoselectivity (de $>95 \%$ ). The hydrogenation of substituted aromatics, however, usually results in a lower diastereoselectivity.

The second important parameter is the catalyst because the different functional groups of the substrates have a different affinity to different noble metal catalysts. Therefore, the diastereoselective hydrogenation of $\mathrm{C}=\mathrm{C}, \mathrm{C}=\mathrm{O}$ and $\mathrm{C}=\mathrm{N}$ bonds proceeds better on palladium, while rhodium or ruthenium usually give better results in the hydrogenation of aromatics. The reaction conditions influence the diastereoselectivity to a lesser extent. Temperature plays a role when it influences the conformational stability of the substrate. The pressure may be important when the reaction proceeds along various pathways, but a significant effect of pressure on diastereoselectivity has not been reported thus far. The solvent usually affects the reaction rate rather than the diastereoselectivity. Nevertheless, all the reaction conditions must be considered in the finetuning of a diastereoselective reaction.

The steric interaction is of prime importance in heterogeneous diastereoselective hydrogenation and probably determines face selectivity, and thus, diastereoselectivity. Therefore, the future of diastereoselective hydrogenation is mainly in chiral auxiliaries, which can be tailored to form rigid and conformationally stable substrates.

\section{Acknowledgments}

We thank Dr. V. Ranade for providing information and data on the diastereoselective hydrogenation of substituted aromatics.

\section{References}

[1] Market Research, Frost \& Sullivan, London (2002).

[2] H.U. Blaser and M. Studer, Appl. Catal. 189 (1999) 191.

[3] A. Tai and T. Harada, in Tailored Metal Catalysts, Y. Iwasawa, (ed.) (D. Reidel, Dordrecht, 1986).
[4] H.U. Blaser, Tetrahedron: Asymmetry 2 (1991) 843.

[5] H.U. Blaser, H.P. Jalett, M. Müller and M. Studer, Catal. Today 37 (1997) 441.

[6] A. Tai, M.N. Morimoto, M. Yoshikawa, K. Uehara, T. Sugimura and T. Kikukawa, Agric. Biol. Chem. 54 (1990) 1753.

[7] R. Schmid and E.A. Broger, Proc. ChiralEurope '94, Spring Innovations 1994, p. 79.

[8] U. Blaser, H.P. Jalett and F. Spindler, J. Mol. Catal. A: Chem. 107 (1996) 85

[9] U. Blaser and H.P. Jalett, Stud. Surf. Sci. Catal. 78 (1993) 139.

[10] M. Studer, S. Burkhard and H.U. Blaser, Chem. Commun. 1727 (1999).

[11] U. Blaser, Ch. Malan, B. Pugin, F. Spindler, H. Steiner and M. Studer, Adv. Synth. Catal. 345 (2003) 103.

[12] M. Studer, H.U. Blaser and C. Exner, Adv. Synth. Catal. 345 (2003) 45.

[13] B. Minder, T. Mallat, A. Baiker, G. Wang, T. Heinz and A Pfaltz, J. Catal. 154 (1995) 371.

[14] R.L. Augustine and S.K. Tanielyan, J. Mol. Catal. 112 (1995) 180.

[15] A. Baiker, J. Mol. Catal. A: Chem. 115 (1997) 473.

[16] A. Vargas, T. Bürgi and A. Baiker, J. Catal. 197 (2001) 378.

[17] M. Besson and C. Pinel, Top. Catal. 5 (1998) 25.

[18] A. Tungler and K. Fodor, Catal. Today 37 (1997) 191.

[19] K. Harada, in Asymmetric Synthesis, Vol. 5, J.D. Morrison, (ed.) (Academic Press, New York, 1985) p. 345.

[20] A. Tungler and G. Foggasy, J. Mol. Catal. A: Chem. 173 (2001) 231.

[21] J. Blacklock, R.F. Shuman, J.W. Butcher, W.E. Shearin, J. Budavari and V.J. Grenda, J. Org. Chem. 53 (1988) 836.

[22] F. Roessler, Chimia 50 (1996) 106.

[23] W. Göhring, S. Gokhale, H. Hilpert, F. Roessler, M. Schlageter and P. Vogt, Chimia 50 (1996) 532.

[24] P. Kukula and R. Prins, J. Catal. 208 (2002) 404.

[25] A. Tungler, M. Kajtar, T. Mathe, G. Toth, E. Fogassy and J. Petro, Catal. Today 5 (1989) 159.

[26] A. Tungler, T. Mathe, J. Petro and T. Tarnai, J. Mol. Catal. 61 (1990) 259

[27] K. Borszeky, T. Mallat, R. Aeschimann, W.B. Schweizer and A. Baiker, J. Catal. 161 (1996) 451.

[28] A. Predrazzoli, Helv. Chim. Acta 40 (1957) 80.

[29] S. Yamada, T. Shioiri and T. Fuji, Chem. Pharm. Bull. 10 (1962) 688.

[30] J.C. Sheehan and R.E. Chandle, J. Am. Chem. Soc. 83 (1961) 4759.

[31] K. Harada and M. Takasaki, Bull. Chem. Soc. Jpn. 57 (1984) 1427.

[32] A. Tungler, A. Fürcht, Z.P. Karancsi, G. Toth, T. Mathe, L. Hegedus and A. Sandi, J. Mol. Catal. 139 (1999) 239.

[33] M. Takasaki and K. Harada, Chem. Lett. 10 (1984) 1745.

[34] M. Oba, S. Nakajima and K. Nishiyama, J. Chem. Soc. Chem. Commun. 1875 (1996).

[35] M. Oba, T. Terauchi, Y. Owari, Y. Imai, I. Motoyama and K. Nishiyama, J. Chem. Soc. Perkin Trans. 11275 (1998).

[36] T. Kanmera, S. Lee, H. Aoyagi and N. Izumiya, Tetrahedron Lett. 46 (1979) 4483.

[37] H. Aoyagi, F. Horike, A. Nakagawa, S. Yokote, N. Park, Y. Hashimoto, T. Kato and N. Izumiya, Bull. Chem. Soc. Jpn. 59 (1986) 323.

[38] N.G. Park, S. Lee, H. Maeda, H. Aoyagi and T. Kato, Bull. Chem. Soc. Jpn. 62 (1989) 2315.

[39] B.W. Bycroft and G.R. Lee, J. Chem. Soc. Chem. Commun. 988 (1975).

[40] K. Bergmann and R. Tietzman, J. Biol. Chem. 155 (1944) 535.

[41] H. Poisel and U. Schmidt, Chem. Ber. 106 (1973) 3408.

[42] S.D. Bull, S.G. Davies, S.W. Epstein, M.A. Leech and J.V.A. Ouzman, J. Chem. Soc., Perkin Trans. 12321 (1998). 
[43] S.D. Bull, S.G. Davies, S.W. Epstein and J.V.A. Ouzman, J. Chem. Soc. Chem. Commun. 659 (1998).

[44] C. Prasad, Peptides 16 (1995) 151.

[45] J.P. Milne, A.L. Hunt, K. Rostoll, J.J. Van der Walt and C.J. Graz, J. Pharm. Pharmacol. 50 (1998) 1331.

[46] C.J.M. Graz, G.D. Grant, S.C. Brauns, A. Hunt, H. Jamie and J.P. Milne, J. Pharm. Pharmacol. 52 (2000) 75.

[47] C. Cui, H. Kakeya and H. Osada, Tetrahedron 52 (1996) 12651.

[48] H. Hayashi, S. Murao and M. Arai, Chem. Exp. 6 (1991) 989.

[49] P. Waring, R.D. Eichner, A. Mullbacher and J. Sjaarda, J. Biol. Chem. 263 (1988) 18493.

[50] C. Takahashi, A. Numata, I. Ito, E. Matsumura, H. Araki, H. Iwaki and K. Kushida, J. Chem. Soc., Perkin Trans. 11859 (1994).

[51] S.D. Bull, S.G. Davies, R.M. Parkin and F. Sanchez-Sancho, J. Chem. Soc., Perkin Trans. 12313 (1998).

[52] P. Kukula and R. Prins, J. Catal. 217 (2003), 240.

[53] C. Cativiela, M.D. Diaz-de-Villegas and J.A. Galves, Tetrahedron: Asymmetry 3 (1992) 567.

[54] D. Seebach, H.M. Bürger and C.P. Schickli, Liebigs Ann. Chem. 7 (1991) 669.

[55] F. von Nussbaum and S.J. Danishefsky, Angew. Chem. 39 (2000) 2175.

[56] H.O. Kim, H. Nakanishi, M.S. Lee and M. Kahn, Org. Lett. 2 (2000) 301 .

[57] H.M. Zhong, J.H. Cohen, A.F. Abdel-Magid, B.D. Kenney, C.A. Maryanoff, R.D. Shah, F.J. Villani, F. Zhang and X. Zhang, Tetrahedron Lett. 40 (1999) 7721.

[58] M. Prashad, Y. Liu, H.-Y. Kim, O. Repic and T.J. Blacklock, Tetrahedron: Asymmetry 10 (1999) 3479.

[59] K. Harada in Asymmetric Synthesis J.D. Morrison, (Ed.) (Academic Press, New York, 1985) Vol. 5, p. 345.

[60] K. Harada and T. Munegumi, Bull. Chem. Soc. Jpn. 57 (1984) 3203.

[61] K. Harada and T. Munegumi, Bull. Chem. Soc. Jpn. 56 (1983) 2774.

[62] T. Munegumi, T. Maruyama, M. Takasaki and K. Harada, Bull. Chem. Soc. Jpn. 63 (1990) 1832.

[63] R.G. Hiskey and R.C. Northrop, J. Am. Chem. Soc. 83 (1961) 4798.

[64] G. Knupp and A.W. Frahm, Arch. Pharm. 318 (1985) 250.

[65] W. Wiehl and A.W. Frahm, Chem. Ber. 119 (1986) 2668.

[66] D.E. Nichols, C.F. Barfknecht, D.B. Rusterholz, F. Benington and R.D. Morin, J. Med. Chem. 16 (1973) 480.

[67] R.T. Standridge, H.G. Howell, J.A. Gylys and R.A. Partyka, J. Med. Chem. 19 (1976) 1400

[68] R.G. Hiskey and R.C. Northrop, J. Am. Chem. Soc. 87 (1965) 1753.

[69] K. Harada, T. Iwasaki and T. Okawara, Bull. Chem. Soc. Jpn. 46 (1973) 1901

[70] G. Bringmann and J.-P. Geisler, Tetrahedron Lett. 30 (1989) 317.

[71] L. Gutman, M. Etinger, G. Nisnevich and F. Polyak, Tetrahedron: Asymmetry 9 (1998) 4369.

[72] M.B.H. Joudim, J.P.M. Finberg, R. Levy, J. Sterling, D. Lerner and T. Berger-Paskin, Eur. Pat. Appl. EP 436, 492.

[73] J. Sterling, R. Levy, A. Veinberg, W. Goldenberg, J. Finberg, M. Youdim and A. Gutman, Eur. Pat. Appl. EP 538, 134.

[74] S. Yamada, N. Ikota and K. Achiwa, Tetrahedron Lett. 13 (1976) 1001.

[75] S. Yamada and S. Hashimoto, Tetrahedron Lett. 13 (1976) 997.
[76] K. Harada and K. Matsumoto, Bull. Chem. Soc. Jpn. 44 (1971) 1068.

[77] K. Harada and K. Matsumoto, J. Org. Chem. 32 (1967) 1794

[78] K. Harada and K. Matsumoto, J. Org. Chem. 33 (1968) 4467.

[79] T.J. Donohoe, R. Garg and C.A. Stevenson, Tetrahedron: Asymmetry 7 (1996) 317.

[80] M. Freifelder, Practical Catalytic Hydrogenation: Techniques and Application (Wiley, New York, 1971).

[81] P. Rylander, Catalytic Hydrogenation in Organic Synthesis (Academic Press, New York, 1979).

[82] P.N. Rylander, Catalytic Hydrogenation over Platinum Metals (Academic Press, New York, 1967).

[83] K. Nasar, F. Fache, M. Lemaire, J.-C. Béziat, M. Besson and P. Gallezot, J. Mol. Catal. 87 (1994) 107.

[84] R. Exl, E. Ferstl, H. Hönig and R. Rogi-Kohlenprath, Chirality 7 (1995) 211.

[85] M. Besson, B. Blanc, P. Gallezot, K. Nasar and C. Pinel, in Catalysis of Organic Reactions, R.E. Malz, Jr., (ed.) (Marcel Dekker, New York, 1996) p. 177.

[86] M. Besson, P. Gallezot, C. Pinel and S. Neto, Stud. Surf. Sci. Catal. 108 (1997) 215.

[87] K. Nasar, M. Besson, P. Gallezot, F. Fache and M. Lemaire, in Chiral Reactions in Heterogeneous Catalysis, G. Jannes and V. Dubois, (eds.) (Plenum Press, New York, 1995) p. 141

[88] M. Besson, P. Gallezot, S. Neto and C. Pinel, Chem. Commun. 1432 (1998).

[89] M. Besson, B. Blanc, M. Campelet, P. Gallezot, K. Nasar and C. Pinel, J. Catal. 170 (1997) 254.

[90] S. Neto, Ph.D. Thesis Nr. 270-98 (L’Université Claude Bernard, Lyon, 1998).

[91] M. Besson, P. Gallezot, S. Neto and C. Pinel, Tetrahedron: Asymmetry 11 (2000) 1809.

[92] V.S. Ranade and R. Prins, J. Catal. 185 (1999) 479.

[93] V.S. Ranade, G. Consiglio and R. Prins, Catal. Lett. 58 (1999) 71.

[94] V.S. Ranade, G. Consiglio and R. Prins, J. Org. Chem. 64 (1999) 8862.

[95] V.S. Ranade, G. Consiglio and R. Prins, J. Org. Chem. 65 (2000) 1132.

[96] M. Feigel, G. Lugert, J. Manero and M. Bremer, Z. Naturforsch. 45b (1989) 258.

[97] L. Hegedus, V. Hada, A. Tungler, T. Mathe and L. Szepesy, Appl. Catal. A 201 (2000) 107.

[98] V. Hada, A. Tungler and L. Szepesy, Appl. Catal. A 210 (2001) 165.

[99] N. Douja, M. Besson, P. Gallezot and C. Pinel, J. Mol. Catal. A: Chem. 186 (2002) 145.

[100] M. Petersen and M. Sauter, Chimia 53 (1999) 608.

[101] D. Askin, K.K. Eng, K. Rossen, R.M. Purick, P.B. Wells, R.P. Volante and P.J. Reider, Tetrahedron Lett. 35 (1994) 673.

[102] C.F. Bigge, G. Johnson, D.F. Ortwine, J.T. Drummond, D.M. Retz, L.J. Brahce, F.W. Marcoux and A.W. Probert, J. Med. Chem. 35 (1992) 1371.

[103] M. Neya, H. Yamazaki, N. Kayakiri, K. Satto and T. Oku, WO 98/27069.

[104] B. De, M.G. Natchus, S. Pikul, N.G. Almstead, R.S. Matthews, Y.O. Taiwo and M. Cheng, WO 98/08825.

[105] M. Cheng, B. De, S. Pikul, N.G. Almstead, M.G. Natchus, M.V. Anastasio, S.J. McPhail, C.E. Snider, Y.O. Taiwo, L. Chen, C.M. Dunaway, F. Gu, M.E. Dowty, G.E. Mieling, M.J. Janusz and S. Wang-Weigand, J. Med. Chem. 43 (2000) 369.

[106] M.A. Bruce, D.R. Laurent, G.S. Poindexter, I. Monkovic, S. Huang and N. Balasubramanian, Synth. Commun. 25 (1995) 2673. 